\title{
Tomographic imaging of the equatorial and low-latitude ionosphere over central-eastern Brazil
}

\author{
Marcio T. A. H. Muella ${ }^{1,2}$, Eurico R. de Paula ${ }^{2}$, Cathryn N. Mitchell ${ }^{3}$, Paul M. Kintner ${ }^{4}$, \\ Ricardo R. Paes ${ }^{2}$, and Inez S. Batista ${ }^{2}$ \\ ${ }^{1}$ Universidade do Vale do Paraíba, Laboratório de Física e Astronomia, IP\&D, São José dos Campos, Sáo Paulo, Brazil, 12244-000 \\ ${ }^{2}$ Instituto Nacional de Pesquisas Espaciais, Divisão de Aeronomia, São José dos Campos, São Paulo, Brazil, 12227-010 \\ ${ }^{3}$ Electronic and Electrical Engineering, University of Bath, Bath, BA2 7AY, UK \\ ${ }^{4}$ School of Electrical and Computer Engineering, Cornell University, Ithaca, 14853, NY, USA
}

(Received August 27, 2010; Revised December 28, 2010; Accepted December 28, 2010; Online published February 28, 2011)

\begin{abstract}
A four-dimensional time-dependent tomographic algorithm, named Multi Instrument Data Analysis System (MIDAS), is used to image the equatorial and low-latitude ionosphere over the central-eastern sides of the Brazilian territory. From differential phase data obtained by a chain of ground-based GPS receiver the total electron content (TEC) is estimated and then, together with a modeled ionosphere from International Reference Ionosphere (IRI) model, the electron density distribution is reconstructed and the parameters of the $F_{2}$-peak layer are accessed from the images. This paper presents the rst study of ionospheric tomography using real dual-frequency data from the Brazilian Network for Continuous GPS Monitoring (RBMC). Ionospheric $F_{2}$ peak electron density $\left(N_{\mathrm{m}} F_{2}\right)$ accessed from the images are compared to concurrent measurements from three ionosondes installed across Brazil. One year of data during the solar maximum period from March/2001 to February/2002 is used to analyze the seasonal and hourly variation of the $F_{2}$-layer peak density. The accuracy with which MIDAS images the electron density during geomagnetic quiet periods is investigated through its correlation and deviation with the ionosonde and IRI model data, respectively. The main aspects of the reconstruction results at the equatorial ionization anomaly (EIA) region over Brazil are highlighted and discussed.
\end{abstract}

Key words: Ionospheric tomography, ionospheric imaging, GPS, TEC, equatorial ionization anomaly, IRI model, digital ionosonde.

\section{Introduction}

A relevant peculiarity of the ionosphere over the Brazilian sector is the fact that it comprises the magnetic equator, the inner edge of the northern crest of the equatorial ionization anomaly (EIA) and beyond the southern anomaly crest. The EIA, characterized for two crests in the ionospheric $F$-region plasma density at either side of the magnetic dip equator (around $\sim 15^{\circ}-20^{\circ}$ ), is one of the most studied phenomena, and the understanding of its morphology and variability is of great interest to improve regional ionospheric models. In fact, the equatorial anomaly can be considered the most signi cant feature of the tropical ionosphere. The EIA crests are the result of the so called 'fountain effect', where plasma is moved upward at the dip equator owing to the electrodynamic $\mathbf{E} \times \mathbf{B}$ drift and then diffuses downward along the magnetic eld lines to higher latitudes (see e.g. Kelley, 2009 and references cited therein). The equatorial anomaly is primarily a daytime structure which starts to develop after sunrise and reaches a maximum at around 14:00 local time (LT). However, a resurgence of the anomaly crests can often be found during post-sunset hours

Copyright (C) The Society of Geomagnetism and Earth, Planetary and Space Sciences (SGEPSS); The Seismological Society of Japan; The Volcanological Society of Japan; The Geodetic Society of Japan; The Japanese Society for Planetary Sciences; TERRAPUB.

doi:10.5047/eps.2010.12.011 as a consequence of the large enhancement of the $F$-region vertical drift (also known as electric eld pre-reversal enhancement) and the rapid uplift of the ionosphere.

The electron density is considered the most important parameter to study the behavior of the equatorial anomaly. Ground-based ionospheric radio soundings and rockets are examples of instruments widely used to monitor the ionospheric electron density (see e.g. Abdu et al., 1990; Walker et al., 1991). Recently, with the availability of a signi cant amount of data sets from Global Navigation Satellite Systems (GNSS), integrated measurements of electron density, also known as total electron content (TEC), have also revealed important features of the equatorial anomaly. TEC measurements have been obtained from ground-based receivers specially developed to detect the signals transmitted by such satellite systems (Davies and Hartmann, 1997). For example, one of the main sources for most experimental measurements of TEC has been obtained from regional networks of Global Positioning System (GPS) receivers. Basically, the receivers measure the resultant phase and group delays of the transmitted L-band signals from different satellite passes, and then combine the data sets in an algorithm to yield values of equivalent vertical total electron content (Kersley et al., 2004). The maximum contribution for TEC comes from the $F_{2}$-layer, where approximately $60 \%$ are from 
those regions above the height of $F_{2}$-peak density $\left(N_{\max }\right)$ (Mendillo, 2006). The TEC measurements can be represented individually for single stations as well as organized into two-dimensional vertical TEC maps, which provide electron density distribution over a regional or global basis. The vertical TEC maps are examples of product routinely available in real-time on the internet from several agencies, which allow investigate the spatial distribution and the horizontal structuring of the ionospheric electron density (see for example Jet Propulsion Laboratory (JPL) global maps of TEC at http://iono.jpl.nasa.gov/; Centre for Orbit Determination at Europe (CODE) global ionosphere maps at http://aiuws.unibe.ch/ionosphere/; National Oceanic and Atmospheric Administration (NOAA) Space Weather Prediction Center regional maps of TEC over USA at http://www.swpc.noaa.gov/ustec; and World Data Center regional maps over Japan at http://wdc.nict.go.jp/IONO.contents/E011_TECmap.html).

In order to investigate the latitudinal structure of the ionization in the equatorial anomaly region on both short and long timescales, and its alignment with the geomagnetic eld and other vertical dynamical changes, measurements of TEC have also been used in a varied number of ionospheric tomographic imaging techniques (see e.g. reviews by Leitinger, 1996; Pryse, 2003; Kersley, 2005; Bust and Mitchell, 2008). In ionospheric tomography the TEC data are analyzed and, subsequently, inverted using a mathematical reconstruction algorithm that yields three-dimensional images of electron density throughout the regions of the satellite-to-ground ray-path intersections. At equatorial and low latitudes ionospheric imaging technique has provided relevant information on the vertical structure of the electron density, its temporal variation and how it is lifted up and transported to other regions. Moreover, tomographic imaging has been applied at different longitude sectors and contributed signi cantly in the understanding of the ionospheric dynamics in the equatorial anomaly region, its seasonal and day-to-day variability and response under different geomagnetic conditions (Huang et al., 1997; Andreeva et al., 2000; Kunitsyn et al., 2003; Thampi et al., 2004). In the South-American sector the rst attempt to reconstruct the ionosphere by using tomographic inversion technique is due to Pakula et al. (1994). In the Brazilian sector a simulation study of tomographic imaging of the equatorial anomaly was presented for the rst time by Materassi and Mitchell (2005a). More recently, Muella et al. (2009, 2010) used experimental results of tomographically reconstructed images to evaluate the ionospheric electron density gradients over Brazil.

TEC database from the existing Brazilian ground-based GPS network have been used to investigate the spatialtemporal variability of TEC. However, in terms of tomographic reconstruction it has not been demonstrated whether the placement of the ground station receivers is adequate for the resolution imaging of the ionospheric $F$ layer peak electron density. A proper knowledge of the electron density horizontal and vertical structuring at equatorial and low latitudes is crucial for current communication/navigation systems, and the access to such information is relevant for the technical and scienti c commu- nities working in the mitigation of positioning errors on GNSS-based applications. This paper is organized as follows: Section 2 presents the Brazilian GPS receiver network from where the collected data were used in this study. Section 3 describes the experiment and methodology. Next, in Section 4, we present and discuss the results of tomographic reconstruction from the existed ground-based GPS receiver network. Finally, we present in Section 5 the concluding remarks.

\section{The Brazilian Dual-Frequency GPS Receiver Network}

The Brazilian Network for Continuous GPS Monitoring (RBMC) was established in 1996 by the Brazilian Institute of Geography and Statistics (IBGE) as the rst active geodetic control in South America. From its rst con guration of nine stations, the Brazilian network of dual-frequency GPS receivers has actually grown to about 50 receivers in operation, and is expected to attain about 70 in the next solar maximum (year 2013). The data from RBMC receivers can be downloaded in the widely accepted standard Receiver INdependent Exchange (RINEX) format at the IBGE Data Center for Geosciences (http://www.ibge.gov.br/english/). Presently, seven RBMC receivers are jointly part of the GPS array managed by the International GPS Service for Geodynamics (IGS). In this work, about 16 dual-frequency GPS receivers installed in the central-eastern side of Brazil throughout the years 2001 and 2002 were used to obtain TEC measurements from the ionospheric delay between the GPS L1 (1575.42 MHz) and L2 $(1227.60 \mathrm{MHz})$ frequencies. Figure 1 shows the location of the RBMC GPS stations (yellow triangles) installed in Brazil during the observation period presented here.

The GPS network over Brazil provides a unique opportunity to study the behavior of the ionosphere by observing the spatial and temporal distribution of TEC in the region between the dip equator and the equatorial anomaly. In the present report we explore the capability for imaging the equatorial anomaly region over Brazil in order to investigate, for the rst time, whether the tomographic reconstruction approach can be used routinely as complement to ionosonde monitoring. Digital ionosonde $F_{2}$-peak density parameter is used to validate the ionospheric reconstructions generated by the four-dimensional inversion algorithm used here.

\section{Data and Method}

In ionospheric radiotomography it has been demonstrated in previous studies that an uneven distribution of ground-based receivers leads to a low number of information content of the dataset which limit the accuracy to monitoring large-scale horizontal ionization structures, and therefore, the resolution images of electron density and TEC can be severely impacted (Na et al., 1995; Zapfe et al., 2006; Muella et al., 2010). For this reason, in the present work a region with a denser and more evenly distributed con guration of receivers was chosen for the measurement of equivalent vertical TEC and application of tomographic reconstruction. According to the studies of Materassi and Mitchell (2005a) and Zapfe et al. (2006), this is considered 


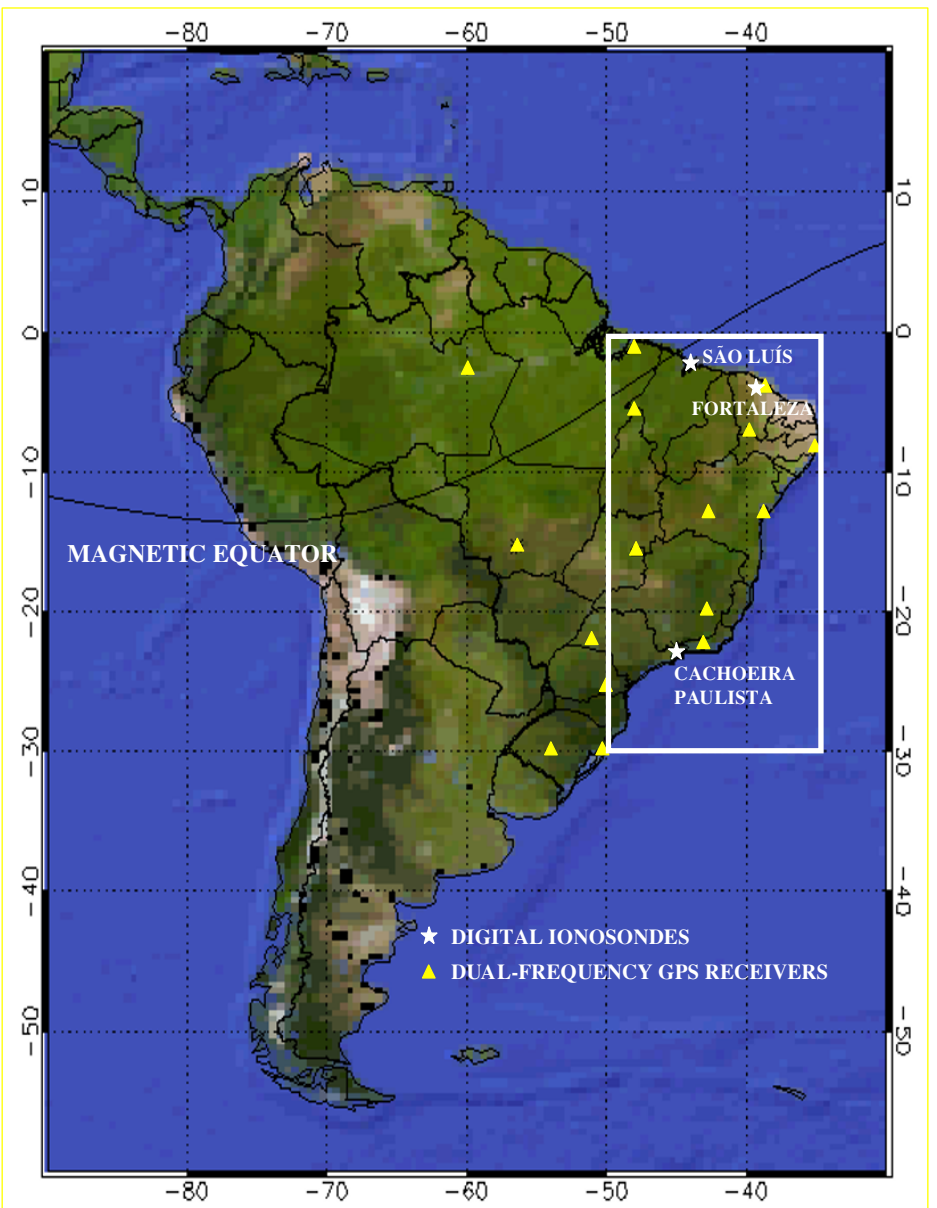

Fig. 1. Location of the dual-frequency GPS receivers (triangles) and digital ionosondes (stars) used in the present study.

the region of low maximum absolute TEC error $(\sim 25 \%$ due to data sparsity) and is represented in Fig. 1 by the area within the white rectangle. This region covers the geographic longitude region of $35^{\circ}-60^{\circ} \mathrm{W}$ and the geographic latitude of $0^{\circ}-35^{\circ} \mathrm{S}$.

In the present work we used a four-dimensional timedependent inversion algorithm developed by researchers from the University of Bath (UK) and named as MultiInstrument Data Analysis System (MIDAS). The use of the MIDAS algorithm can be found in recent works for different latitudes and longitudinal sectors (see for example, Cilliers et al., 2004; Dear and Mitchell, 2007). The GPS navigation and observation data from RBMC/IBGE receivers were acquired at sampling intervals of $15 \mathrm{sec}$ and used as input to the MIDAS tomographic algorithm. Precise orbit files were obtained from IGS/JPL home pages at 〈http://igscb.jpl.nasa.gov/CORS/Gpscal.html〉 and also used as input to the MIDAS system. The program computes the slant TEC along the ray paths of all satellites visible from the set of dual-frequency GPS receivers. Each set of slant TEC data are combined into the MIDAS algorithm to perform four-dimensional constrained inversion of electron density images. The solution can be constrained in any way and here is done using a priori information from the International Reference Ionosphere (IRI-2001) model (Bilitza, 2001), where the sample space of solutions of electron density is defined by a combination of empirical orthogonal functions (EOFs). The choice of orthonormal basis functions is critical in the determination of the final solution (Mitchell and Spencer, 2003); here this is limited in the vertical profile shape by the IRI-2001 model. The unknown electron density is represented by a linear combination of orthogonal vertical profiles (modeled) obtained using singular value decomposition, horizontally modulated by spherical harmonics (whose coefficients are linearly dependent on time). The number of EOF bases (latitudinal and longitudinal harmonics) used in the modeling of the vertical distribution of electron density followed the recommendations given by Zapfe et al. (2006). Three EOFs were used in the present analysis. A complete outlining of the main steps of the tomographic reconstruction from MIDAS can be found in the works of Mitchell and Spencer (2003) and Materassi and Mitchell (2005b), and therefore the full mathematical description of the method will not be repeated here. Timeevolving images of electron density within the geographical region depicted in Fig. 1 were reconstructed by the MIDAS algorithm in intervals of $1 \mathrm{~h}$.

The resulting images ranged from $80 \mathrm{~km}$ to $1080 \mathrm{~km}$ in altitude and were generated using a grid of $0.5^{\circ}$ latitude by $2^{\circ}$ longitude and $20 \mathrm{~km}$ altitude. It should be noted that this is not the resolution of the image; rather it is the discretisation. The resolution is defined by the wavelengths of the harmonics and the EOFs profiles. The EOFs are particularly relevant here because they limit the range of scale 
that is possible in the reconstructed image which will have subsequent effects in the value of the electron density at the $F$-layer peak. The top height of $1080 \mathrm{~km}$ of the reconstruction grid was chosen to minimize the contribution of the plasmasphere. From the GPS-reconstructed images the quantity assessed was the maximum electron density at the $F$-layer peak height $\left(N_{\max }\right)$. The mean hourly variation of this parameter during different seasonal periods throughout the solar maximum year from March/2001 to February/2002 is compared with measurements from three digital ionosondes installed in Brazil; São Lu's $\left(2.3^{\circ} \mathrm{S} ; 44^{\circ} \mathrm{W}\right.$; magnetic lat. $\left.0.8^{\circ} \mathrm{S}\right)$, Fortaleza $\left(3.8^{\circ} \mathrm{S} ; 38.0^{\circ} \mathrm{W}\right.$; magnetic lat. $\left.5.5^{\circ} \mathrm{S}\right)$ and Cachoeira Paulista $\left(22.4^{\circ} \mathrm{S} ; 45^{\circ} \mathrm{W}\right.$; magnetic lat. $\left.17.2^{\circ} \mathrm{S}\right)$. The location of these three ionosonde stations is indicated as white stars in Fig. 1. The ionospheric parameter scaled from the ionograms recorded by the ionosondes, and used to test the accuracy of the tomographic images, was the peak electron density $\left(N_{\mathrm{m}} F_{2}\right)$ (computed from the critical frequency of the $F_{2}$-layer $\left.\left(f_{\mathrm{o}} F_{2}\right)\right)$. The main objective here is to analyze the regions of validity of the electron density reconstructed over Brazil from the GPS-based MIDAS tomographic algorithm. Such results will determine the feasibility and con dence of the technique for the existing receiver con guration and what improvements to expect in subsequent research during the next solar maximum active period. The analysis during solar maximum is important because this is the epoch when the ionosphere is denser and ticker at the equatorial anomaly crests surrounding the magnetic equator.

\section{Results and Discussions}

Figure 2 shows two-dimensional (geog. latitudelongitude) sliced maps of equivalent vertical TEC and two-dimensional (latitude-altitude) reconstructed electron density images. The vertical TEC values were obtained by applying a geometrical correction on the slant TEC and assuming an ionospheric shell at $400 \mathrm{~km}$. We have chosen a day during the June solstice (local winter) and December solstice (local summer) months which represents closely the mean ionospheric and geomagnetic (quiet) conditions during the period analyzed. The vertical TEC and reconstructed electron density plots in Fig. 2 are shown at 12:00, 19:00 and 23:00 UT (BST $=\mathrm{UT}-3 \mathrm{~h}$ ). For both seasons it is clearly noticed from the images in Fig. 2 evidences of the EIA, with the southern crest reconstructed particularly well. The daily variation in TEC is apparent at the three speci c hours during both the winter (01 July, 2001) and summer (25 February, 2002) cases. After sunrise an enhancement is seen in TEC at 12:00 UT (09:00 BST) during both the days. At 19:00 UT (16:00 BST) large values of vertical TEC is found around $10^{\circ} \mathrm{S}$ on July 1 and between $10^{\circ}-15^{\circ} \mathrm{S}$ on February 25 . At 23:00 UT (20:00 BST) the largest values are seen around $15^{\circ} \mathrm{S}$ on July 1 and $20^{\circ} \mathrm{S}$ on February 25. The cross-sectional images of reconstructed electron density (at $45^{\circ} \mathrm{W}$ ) in Fig. 2 reveal spatial structures which are in accordance with that observed in the TEC plots. Due to production of ionization an enhancement in the electron concentration is seen around 12:00 UT with maximum $N_{\mathrm{e}} \approx 12 \times 10^{11} \mathrm{~m}^{-3}$ on July 1 and $22 \times 10^{11} \mathrm{~m}^{-3}$ on February 25 . The electron density grows up to about $17 \times 10^{11} \mathrm{~m}^{-3}$ at 19:00 UT on July 1, whereas on February 25 it is $\sim 35 \times 10^{11} \mathrm{~m}^{-3}$ between about $6^{\circ}-15^{\circ} \mathrm{S}$ at 19:00 UT. At 23:00 UT the enhancement $\left(N_{\mathrm{e}} \approx 13 \times 10^{11} \mathrm{~m}^{-3}\right)$ migrates to more southern latitudes up to about $15^{\circ} \mathrm{S}$ on July 1 and attains $\sim 35 \times 10^{11} \mathrm{~m}^{-3}$ up to about $20^{\circ} \mathrm{S}$ on February 25. The high values of TEC and electron density at 19:00 and 23:00 UT are related, respectively, to the physical structures of the diurnal EIA and its resurgence after sunset. The seasonal effects on the spatial distribution and magnitude of the electron density is also evidenced in the images, for which on February 25 (local summer) the electron density is larger and the southern crest extends to a much wider latitude range over Brazil than on July 1 (local winter). The graphs in Fig. 2 reveal that the spatial features of the equatorial anomaly can be investigated over part of the Brazilian tropical region by using ionospheric tomography technique.

In order to check the potential accuracy of the tomographic algorithm in reconstructing the electron density, by using real TEC data obtained from the Brazilian network of dual-frequency GPS receivers, Fig. 3 shows mass plots of the ionospheric $F$-layer peak electron density $\left(N_{\mathrm{m}} F_{2}\right)$. The upper and bottom panels in Fig. 3 present, respectively, the daily variations during different seasonal periods of the ionosonde-derived parameter and those assessed from the GPS ionospheric tomographic reconstructions. The three seasonal groups represented here are March-April/September-October (Equinox), May-August (June Solstice) and November-February (December solstice). The plots are shown for the three stations used in this study: São Lu's, Fortaleza and Cachoeira Paulista (hereafter referred as SL, FZ and CP, respectively). The thick black lines in these plots denote the hourly mean values and the dashed gray lines the daily measurements (top panels) or reconstructions (bottom panels) of the $N_{\mathrm{m}} F_{2}$ parameter.

By analyzing in Fig. 3 the measured and the tomographically reconstructed $N_{\mathrm{m}} F_{2}$ it is seen for the grid points of the equatorial stations of SL and FZ that the GPSreconstructed values are in general close to those measured by the ionosondes between 00:00-12:00 UT (nighttime and early morning in the Brazilian longitudinal sector). On the other hand, at the low-latitude of $\mathrm{CP}$ the reconstructed values tend to be lower than the ionosondederived values before 06:00 UT (03:00 BST) and after 21:00 UT (18:00 BST). After 12:00 UT (09:00 BST) and until close the pre-dusk hours $(\sim 21: 00$ UT) the MIDAS $F_{2}$-peak densities seem to be overestimated in relation to the ionosonde-derived values of $N_{\mathrm{m}} F_{2}$ for the sites of SL and FZ. Over CP the agreement is better after 06:00 UT during Equinox months (Mar-Apr/Sep-Oct) but depending on hour the GPS-reconstructed values may be larger than the ionosonde measurements. Otherwise, during the June (May-Aug) and December solstice (Nov-Feb) months the tomographic reconstructed values during daytime (after 09:00 UT and before 21:00 UT) are, respectively, underestimated and overestimated in relation to the ionosonde $F_{2}$ peak densities. A comparison between ionosonde and MIDAS $N_{\mathrm{m}} F_{2}$ for SL, FZ and CP are also presented in Table 1. The correlation coef cients $(R)$ and the slopes $(m)$ of the $\mathrm{t}$ ted lines of the $F_{2}$-layer peak density are summarized in this 

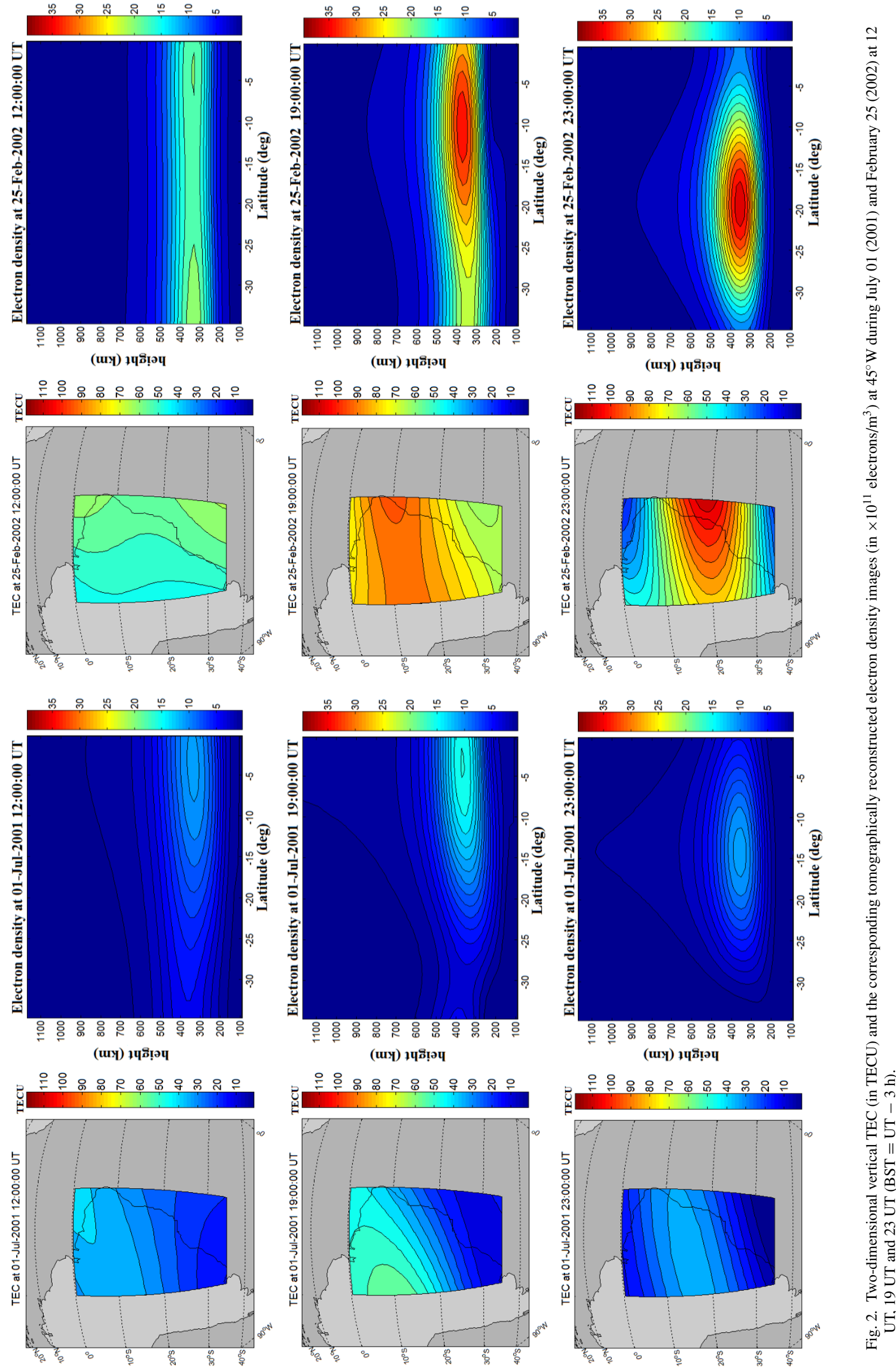

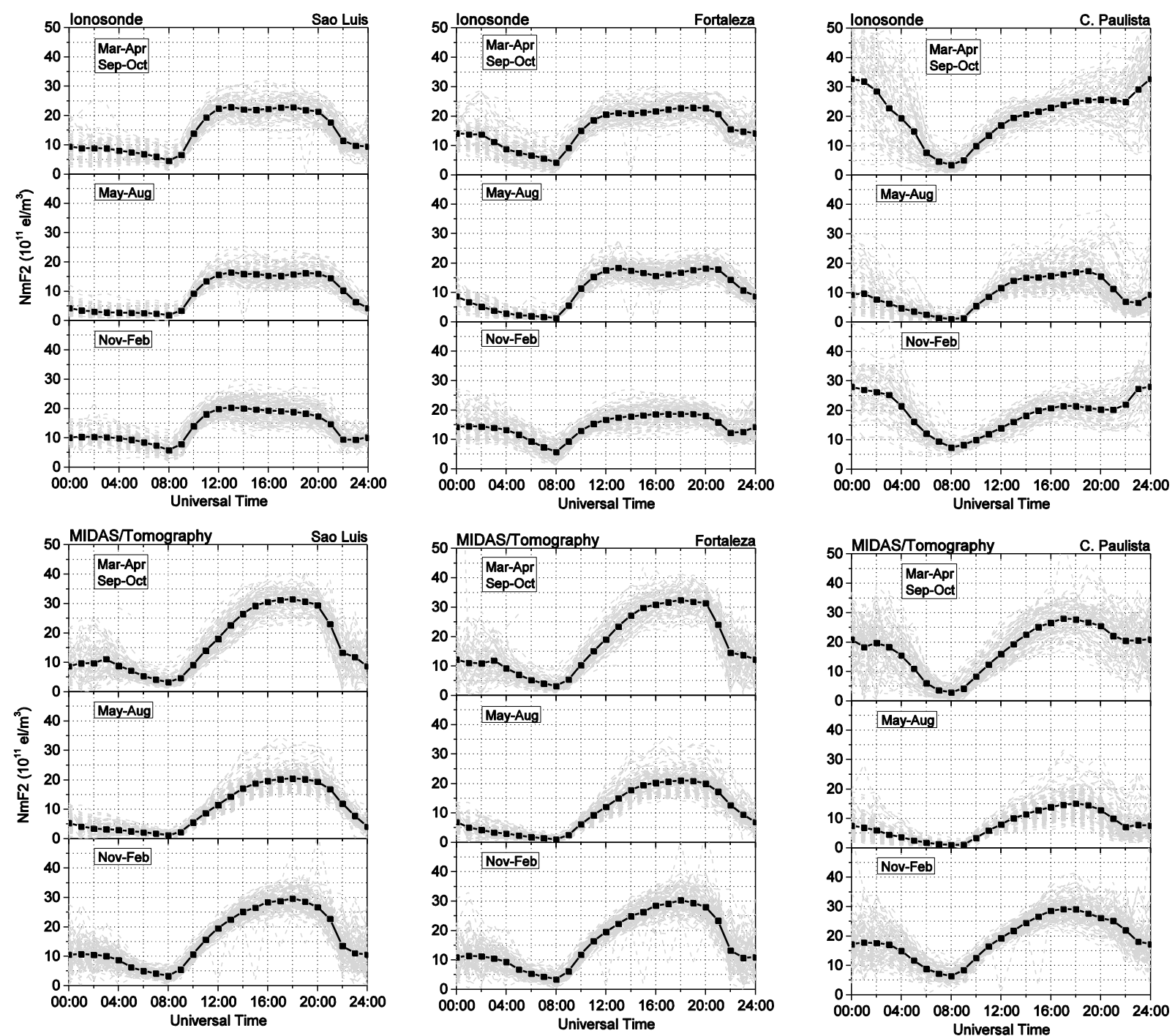

Fig. 3. Seasonal and hourly variation of $N_{\mathrm{m}} F_{2}$ over the stations of SL, FZ and CP as derived from ionosonde measurements (top panels) and reconstructed from dual-frequency GPS data (bottom panels).

Table 1. Seasonal correlation coefficients $(R)$ and slopes $(m)$ between the ionosonde-derived and GPS-reconstructed (MIDAS) $N_{\mathrm{m}} F_{2}$ at the stations of SL, FZ and CP. The acronym $N$ stands for number of data points.

\begin{tabular}{llccc}
\hline Season & Station & $N$ & \multicolumn{2}{c}{$N_{\mathrm{m}} F_{2}$} \\
\cline { 4 - 5 } & & & $R$ & $m$ \\
\hline Equinox & SL & 1882 & 0.93 & 1.35 \\
& FZ & 1951 & 0.93 & 1.56 \\
& $\mathrm{CP}$ & 1769 & 0.83 & 0.74 \\
\hline June Solstice & $\mathrm{SL}$ & 2092 & 0.94 & 1.14 \\
& $\mathrm{FZ}$ & 2380 & 0.92 & 1.07 \\
& $\mathrm{CP}$ & 2298 & 0.98 & 0.84 \\
\hline December Solstice & $\mathrm{SL}$ & 2344 & 0.91 & 1.66 \\
& $\mathrm{FZ}$ & 2332 & 0.92 & 2.06 \\
& $\mathrm{CP}$ & 1502 & 0.51 & 0.59 \\
\hline
\end{tabular}

table. The correlation coefficients of the peak electron density are high (>90\%) for the equatorial sites of SL and FZ during all seasons. However, there is an overestimation of the GPS-reconstructed electron density for SL and FZ in all comparisons as evidenced from the slopes $m$ (larger than 1) presented in Table 1 . The slopes at SL and FZ are very high during December solstice and Equinox months but they are less than $15 \%$ during the June solstice months. The overes- 

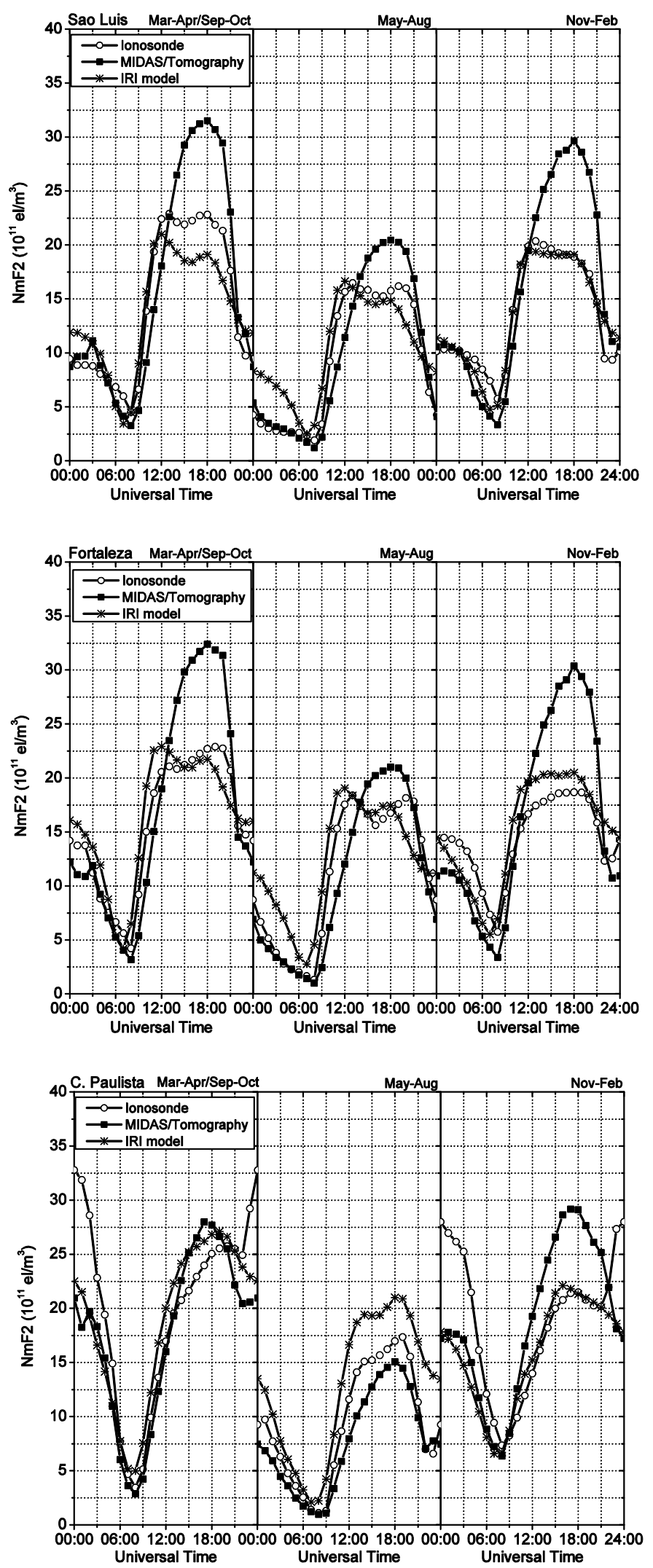

Fig. 4. Comparison of $N_{\mathrm{m}} F_{2}$ derived from ionosonde measurements (line with blanket circles), MIDAS' tomographic reconstructions (line with filled squares) and IRI-2007 model estimations (line with asterisks) during all seasons. Top: equatorial station of SL. Middle: equatorial station of FZ. Bottom: low-latitude station of CP. 
Table 2. Nighttime and daytime deviations of $N_{\mathrm{m}} F_{2}$ (in percentage) for all seasons as estimated from IRI-2007 model with respect to the GPS-reconstructed (MIDAS) and ionosonde-derived values.

\begin{tabular}{lcrrrr}
\hline \multirow{2}{*}{ Season } & Station & \multicolumn{2}{c}{ MIDAS } & \multicolumn{2}{c}{ Ionosonde } \\
\cline { 3 - 5 } & & \multicolumn{1}{c}{ Day } & Night & \multicolumn{1}{c}{ Day } & Night \\
\hline Equinox & SL & $28.3 \%$ & $-5.6 \%$ & $10.6 \%$ & $-3.2 \%$ \\
& FZ & $16.7 \%$ & $-18.0 \%$ & $-2.1 \%$ & $-6.5 \%$ \\
& CP & $-11.3 \%$ & $-13.7 \%$ & $-12.3 \%$ & $16.1 \%$ \\
\hline June Solstice & SL & $7.1 \%$ & $-33.2 \%$ & $0.7 \%$ & $-33.9 \%$ \\
& FZ & $-4.8 \%$ & $-41.7 \%$ & $-3.1 \%$ & $-31.7 \%$ \\
& CP & $-42.5 \%$ & $-47.5 \%$ & $-27.8 \%$ & $-34.9 \%$ \\
\hline December Solstice & SL & $26.5 \%$ & $-6.7 \%$ & $1.1 \%$ & $3.8 \%$ \\
& FZ & $19.1 \%$ & $-17.8 \%$ & $-11.1 \%$ & $8.1 \%$ \\
& $\mathrm{CP}$ & $24.2 \%$ & $7.9 \%$ & $-5.2 \%$ & $40.6 \%$ \\
\hline
\end{tabular}

timation for the equatorial stations coincides with the fact that such sites are located close to the edges of the reconstructed area where the images may be adversely affected. For the low latitude station of CP the correlation is the highest during June solstice months but during the December solstice the two $N_{\mathrm{m}} F_{2}$ are poorly correlated. In an opposite way of that observed for the equatorial stations, for $\mathrm{CP}$ the slopes being less than one reveal that MIDAS underestimates the $N_{\mathrm{m}} F_{2}$ in the region of the EIA crest. The most signi cant underestimation in the reconstructed peak electron density (of $\sim 41 \%$ ) also occurred during the December solstice season. The information about tomographic reconstruction of electron density becomes more problematic in a highly dynamic ionosphere, such as the equatorial anomaly region where the ionospheric gradients are large. The largest density gradients are found to occur in an environment of increased background electron density, such as the regions adjacent to the crests of the EIA. Moreover, the pattern of electron density variations at latitudes of the EIA are directly associated with the variability of the fountain effect. Therefore during December solstice months the density gradients are steeper owing to the enhanced fountain effect. Thus, is plausible that the discrepancies between the GPS-reconstructed (MIDAS) and ionosonde-derived $N_{\mathrm{m}} F_{2}$ are more signi cant during the December solstice than the other seasons.

The panels in Fig. 4 show a comparison of the ionosondederived and the GPS-reconstructed seasonal averaged $N_{\mathrm{m}} F_{2}$ with the modeled (used here the IRI-2007 model outputs) $F_{2}$-peak density for the three stations; SL (top panel), FZ (middle panel) and CP (bottom panel). In Table 2 the deviation percentage of the GPS-reconstructed and ionosondederived $N_{\mathrm{m}} F_{2}$ with respect to the IRI-2007 model are summarized. It is imperative to mention that to form the vertical domain of the GPS reconstructions into MIDAS was used the IRI-2001 model, whereas in Fig. 4 the comparisons are made with outputs of the newer IRI-2007 model, whose updates are mostly signi cant for the topside ionosphere (Bilitza and Reinisch, 2008). The graphs in Fig. 4 and Table 2 reveal distinguishing features for the three stations. In $\mathrm{SL}$ it is noted for all seasons that the IRI model $N_{\mathrm{m}} F_{2}$ during daytime (mainly between 12:00 and 21:00 UT) is lower than the GPS-reconstructed values, but is in good agreement with the ionosonde-derived peak electron densities (as also reported in the work of Batista and Abdu
(2004)), except during the Equinox when it is underestimated in about $11 \%$. In the nighttime (from 00:00 to 06:00 UT) the mostly marked difference occurred during the June solstice months when IRI estimation was larger than the GPS-reconstructed and ionosonde-derived $F_{2}$-peak densities at both SL and FZ. In FZ the daytime and nighttime features are almost the same of that observed in SL with respect to the GPS-reconstructed $N_{\mathrm{m}} F_{2}$. However, the deviations in FZ are $\sim 8-12 \%$ lower during daytime and $\sim 8-12 \%$ larger during nighttime than for the equatorial site of SL. In comparison with the ionosonde-derived values the IRI model $N_{\mathrm{m}} F_{2}$ is somewhat lower $(\sim 8 \%)$ in nighttime (from 00:00 to 06:00 UT) during the December solstice months. For the low-latitude station of CP it is noted that the IRI model $N_{\mathrm{m}} F_{2}$ are underestimated in relation to the ionosonde-derived values during nighttime of the Equinox and December solstice months. With respect to the GPS-reconstructed values the most signi cant disagreement at $\mathrm{CP}$ occurred during the December solstice when the IRI estimations seem to be underestimated. During the June solstice the IRI model $N_{\mathrm{m}} F_{2}$ at CP is systematically larger than the ionosonde-derived (between about 27-35\%) and the GPS-reconstructed ( $>42 \%$ ) $F_{2}$-peak electron densities.

Discrepancies with the GPS-reconstructed values can in part be explained by the fact that tomographic imaging using ground-based GPS data has a limited viewing angle of the line-integrated satellite-receiver path (Cilliers et al., 2004; Dear and Mitchell, 2007). Thus it is possible that the IRI-2001 density pro les used here to constrain the inversions are not distributing the electron density correctly over the imaging area investigated (as depicted in Fig. 1). In addition, as the reconstructions at the centre of the 1-h window were used in the analysis, it is possible that for certain hours the averaging in the GPS-derived data have missed the increases and decreases in $N_{\mathrm{m}} F_{2}$. Moreover, as reported by $\mathrm{Na}$ et al. (1995), the ground station number and spacing are crucial in ionospheric tomography. Ideally, the groundbased receivers should be evenly distributed as to produce uniform projections from propagations paths covering the imaging region. However, the distribution of receivers used in this work can be considered to have a major impact in the reliability of the images, once that the accuracy in the reconstructions is directly associated to the amount of information that has been measured from the vertical pro les. It basically means that in our solution, depending on location, 
the electron density pro le is probably falling back onto the constraint that we put in.

\section{Remarks and Conclusions}

In this study the main ionospheric parameter of $F_{2}$-peak electron density $\left(N_{\mathrm{m}} F_{2}\right)$ obtained from 4-D tomographic inversion of GPS-based TEC, by means of the Brazilian Network for Continuous GPS Monitoring, was compared for the rst time with concurrent measurements of ionograms recorded at stations located close to the magnetic equator and under the southern crest of the EIA (in the centraleastern side of Brazil). The results revealed that for the scenario of existing ground-based GPS receivers, the GPSreconstructed values from MIDAS compared well with the ionograms and delivered high correlations, between $83 \%$ and $98 \%$. The only exception occurred for the low latitude station of $\mathrm{CP}$ (close to the crest of the EIA) during the December solstice months. For the equatorial stations (SL and FZ) and mainly during Equinox and December solstice months MIDAS tend to overestimate $N_{\mathrm{m}} F_{2}$, whereas at latitudes of the anomaly crest (over CP) MIDAS consistently underestimated $N_{\mathrm{m}} F_{2}$. The best agreement between the MIDAS-reconstructed and the ionosonde-derived $N_{\mathrm{m}} F_{2}$ occurred for all stations during June solstice months.

This paper has also demonstrated that the agreement between the GPS-reconstructed and the ionosonde-derived electron density for the equatorial stations is better in nighttime for all seasons, while at latitudes of the anomaly crest the agreement is better during daytime. The tomographic imaging of the ionosphere over Brazil with the existing ground-based GPS receivers revealed to be much more adequate in imaging the horizontal positions of the southern anomaly crest, but there exist some limitation in terms of its vertical resolution. Such differences between the GPSderived and the ionosonde-derived values can be attributed to the basis function used, which may not be exactly replicating the vertical structure of the ionosphere, and also due to the unevenly distribution of the GPS receivers. For the former a solution is to implement a method to improve the basis set of vertical pro les by including into MIDAS algorithm, for example, real ionosonde, radio-occultation or Communication/Navigation Outage Forecasting System (C/NOFS) data. This solution with ionosonde data included has been demonstrated by Dear and Mitchell (2007), at least for mid-latitudes, to produce better peak electron density values without affecting the accuracy in vertical TEC representation. For the latter the solution is to increase the number and density of GPS receivers within the area of reconstruction, which will be throughout the next solar maximum years more than twice the present con guration. A further improvement could also arise from the assimilation of in situ data from the DMSP spacecraft (Pokhotelov et $a l ., 2008)$. The augmentation of the tomographic reconstructions with these modi cations is expected to improve signi cantly the ability of the technique in determining important ionospheric parameters, such as TEC and $N_{\mathrm{m}} F_{2}$.

It is also important to remark some relevant aspects of the effects of satellite-to-Earth measurement geometry on ionospheric tomography technique. For example, as GPS satellites are high in altitude, an excess TEC from plasma- spheric origin may affect the reconstruction electron density. This may occur drastically during storm-time period when reproductions of short-term variabilities are desired. It is rather dif cult to represent the behavior of the ionosphere above the top height because only average conditions are reproduced into the tomographic algorithm by the ionospheric model (Materassi et al., 2003). Thus such averaging, in turn, tended to minimize here the effects of the plasmasphere on the ionospheric reconstruction results. In another case, whether the number of satellite-to-receiver ray paths reduces to a situation that only high elevation satellite signals are detected, the reconstructed electron density may become poorly de ned, even with the use of a set of vertical orthonormal functions. To overcome this, an assessment of quality of the electron density reconstructions was applied as suggested by Materassi and Mitchell (2005a) and used to eliminate from the analysis the days or period of time with large percentage error in mean $N_{\mathrm{m}} F_{2}$ density.

Comparison of the IRI-2007 with the ionosonde-derived and GPS-reconstructed $N_{\mathrm{m}} F_{2}$ in different seasons shows that, at equatorial latitudes, the averaged seasonally $N_{\mathrm{m}} F_{2}$ in daytime is underestimated in relation to the GPS-derived reconstructions, whereas in respect to the ionosonde measurements the deviations are comparatively low. Regarding the low latitude station of $\mathrm{CP}$ (at near EIA crest) IRI model underestimated $N_{\mathrm{m}} F_{2}$, in comparison with the ionosonde-derived values, in nighttime during the equinox and December solstice months. Whereas with respect to the GPS-derived $N_{\mathrm{m}} F_{2}$ the largest deviations occurred in daytime when the IRI model $F_{2}$-peak densities are overestimated during June solstice months and underestimated during December solstice months. Therefore, these observations suggests that depending on local time and season, IRI model can yet not predict accurately the regional variation of the ionosphere above Brazil, and the GPS-data combined with other local ionospheric data would enhance the accuracy of MIDAS in estimating ionospheric parameters and structural peculiarities of the ionosphere at equatorial anomaly region.

Acknowledgments. "Regrettably, Paul M. Kintner Jr. passed away on November 16, 2010. As head of the GPS Laboratory at Cornell University, Paul Kintner strongly collaborated with the INPE's GPS group in the deployment of the Brazilian GPS network for ionospheric scintillation monitoring, actually one of the largest in South-America. It was 13 years of enthusiastic and fruitful collaboration. Along this time Paul was frequently visiting Brazil during the summer, advising his graduate students in the research campaigns. In one of his research trips I was honored to know him. Then during the academic year 20062007 I had the great opportunity to be mentored by him in a program of non-degree Ph.D student at Cornell. This paper is the last one that was missing as result of my research activities with Paul. It will be impossible not to recognize how important he was in my professional development." Marcio Muella Marcio Muella acknowledges the post-doctoral fellowship provided by Fundação de Amparo à Pesquisa do Estado de São Paulo (FAPESP) under project No. 2008/04892-5. This research was also partially supported by the Coordenação de Aperfeiçoamento de Pessoal de N'vel Superior (CAPES) under project No. BEX3367/05-3 and performed while Marcio Muella was enrolled in a program as nondegree Ph.D. student at Cornell University. The authors are grateful to Instituto Brasileiro de Geogra a e Estat'stica (IBGE) for provision of dual-frequency GPS 
receiver data. Cathryn Mitchell acknowledges support from the Royal Society and the UK EPSRC. The authors would also like to thank Maria G. de Aquino for ionosonde data treatment.

\section{References}

Abdu, M. A., G. O. Walker, B. M. Reddy, J. H. A. Sobral, B. G. Fejer, T. Kikuchi, N. B. Trivedi, and E. P. Szuszczewicz, Electric- eld versus neutral wind control of the equatorial anomaly under quiet and disturbed condition-A global perspective from sundial 86, Ann. Geophys., 8, 419-430, 1990.

Andreeva, E. S., S. J. Franke, K. C. Yeh, and V. E. Kunitsyn, Some features of the equatorial anomaly revealed by ionospheric tomography, Geophys. Res. Lett., 27, 2465-2468, 2000.

Batista, I. S. and M. A. Abdu, Ionospheric variability at Brazilian low and equatorial latitudes: comparison between observations and IRI model, Adv. Space Res., 34, 1894-1900, 2004.

Bilitza, D., International reference ionosphere 2000, Radio Sci., 36, 261275, 2001.

Bilitza, D. and B. W. Reinisch, International Reference Ionosphere 2007: Improvements and new parameters, Adv. Space Res., 42, 599-609, 2008.

Bust, G. S. and C. N. Mitchell, History, current state, and future directions of ionospheric imaging, Rev. Geophys., 46, RG1003, doi:10. 1029/2006RG000212, 2008.

Cilliers, P. J., B. D. L. Opperman, C. N. Mitchell, and P. J. Spencer, Electron density pro les determined from tomographic reconstruction of total electron content obtained from GPS dual frequency data: rst results from the South African network of dual frequency GPS receivers stations, Adv. Space Res., 34, 2049-2055, 2004.

Davies, K. and G. K. Hartmann, Studying the ionosphere with the Global Positioning System, Radio Sci., 32, 1695-1703, 1997.

Dear, R. M. and C. N. Mitchell, Ionospheric imaging at mid-latitudes using both GPS and ionosondes, J. Atmos. Sol-Terr. Phys., 69, 817-825, doi:10.1016/j.jastp.2006.06.001, 2007.

Huang, C. R., C. H. Liu, H. C. Yeh, and W. K. Tsai, The low-latitude ionospheric tomography network (LITN)-Initial results, J. Atmos. SolTerr. Phys., 59, 1553-1567, 1997.

Kelley, M. C., The Earth's Ionosphere: Plasma Physics and Electrodynamics, International geophysic series, v.96,2nd edition, Academic Press, 2009.

Kersley, L., Ionospheric tomography and its applications in radio science and geophysical investigations, Ann. Geofis., 48, 535-548, 2005.

Kersley, L., D. Malan, S. E. Pryse, L. R. Cander, R. A. Bamford, A. Belehaki, R. Leitinger, S. M. Radicella, C. N. Mitchell, and P. S. J. Spencer, Total electron content-A key parameter in propagation: measurement and use in ionospheric imaging, Ann. Geofis., 47, 1067-1091, 2004.

Kunitsyn, V. E., E. S. Andreeva, S. J. Franke, and K. C. Yeh, Tomographic investigations of temporal variations of the ionospheric electron density and the implied uxes, Geophys. Res. Lett., 30, 1851, doi:10. 1029/2003GL016908, 2003.

Leitinger, R., Tomography, in Modern Ionospheric Science, edited by Kohl, H., R. Rüster, and K. Schlegel, 346-370, Katlenburg-Lindau: Max-Planck-Institut für Aeronomie, 1996.

Materassi, M. and C. N. Mitchell, Imaging of the equatorial ionosphere, Ann. Geofis., 48, 477-482, 2005a.
Materassi, M. and C. N. Mitchell, A simulation study into constructing of the sample space for ionospheric imaging, J. Atmos. Sol-Terr. Phys., 67, 1085-1091, 2005b.

Materassi, M., C. N. Mitchell, and P. S. J. Spencer, Ionospheric imaging of the northern crest of the Equatorial Anomaly, J. Atmos. Sol-Terr. Phys., 65, 1393-1400, 2003.

Mendillo, M., Storms in the ionosphere: Patterns and processes for total electron content, Rev. Geophys., 44, RG4001, doi:10. 1029/2005RG000193, 2006.

Mitchell, C. N. and P. S. J. Spencer, A three-dimensional time-dependent algorithm for ionospheric imaging using GPS, Ann. Geofis., 46, 687696, 2003.

Muella, M. T. A. H., E. R. de Paula, C. N. Mitchell, and P. M. Kintner, On the evaluation of $\mathrm{Ne}$ gradients at equatorial and low-latitudes during geomagnetically quiet and disturbed periods, Eos Trans. AGU, 90(52), Fall Meet. Suppl., Abstract SA33A-1438, 2009.

Muella, M. T. A. H., E. A. Kherani, E. R. de Paula, A. P. Cerruti, P. M. Kintner, I. J. Kantor, C. N. Mitchell, I. S. Batista, and M. A. Abdu, Scintillation-producing Fresnel-scale irregularities associated with the regions of steepest TEC gradients adjacent to the equatorial ionization anomaly, J. Geophys. Res., 115, A03301, doi:10.1029/2009JA014788, 2010 .

$\mathrm{Na}, \mathrm{H} ., \mathrm{B}$. Hall, and E. Sutton, Ground station spacing effects in ionospheric tomography, Ann. Geophys., 13, 1288-1296, 1995.

Pakula, W. A., D. N. Anderson, M. Beauder, J. Bendito, P. H. Doherty, J. Eicher, P. F. Fougere, L. F. Hughes, R. Inzirillo, N. Jakowski, M. Kapel, J. A. Klobuchar, H. Kuenzler, H. G. Kugland, C. Lottig, R. Leitinger, R. Maderbacher, J. R. Manzano, T. D. Raymund, V. H. Rios, R. Sheehan, B. Trepanier, C. Valladares, and J. Whit eld, Initial total electron content results from the Pan-American ionospheric tomography campaign, in Proceedings of the Beacon Satellite Symposium, edited by Kersley, L., 266-269, University of Wales Aberystwyth: UK, 1994.

Pokhotelov, D., C. N. Mitchell, P. S. J. Spencer, M. R. Hairston, and R. A. Heelis, Ionospheric storm time dynamics as seen by GPS tomography and in situ spacecraft observations, J. Geophys. Res., 113, A00A16, doi: 10.1029/2008JA013109, 2008.

Pryse, S. E., Radio tomography: A new experimental technique, Surveys Geophys., 24, 1-38, 2003.

Thampi, S. V., T. K. Pant, S. Ravindran, C. V. Devasia, and R. Sridharan, Simulation studies on the tomographic reconstruction of the equatorial and low-latitude ionosphere in the context of the Indian tomography experiment: CRABEX, Ann. Geophys., 22, 3445-3460, 2004.

Walker, G. O., T. Y. Y. Li, J. Soegijo, T. Kikuchi, Y. N. Huang, V. Badillo, and E. P. Szuszczewicz, North-South asymmetry of the equatorial ionospheric anomaly observed in the east-Asia during the sundial-87 campaign, Ann. Geophys., 9, 393-400, 1991.

Zapfe, B. D., M. Materassi, C. N. Mitchell, and P. Spalla, Imaging of the equatorial ionospheric anomaly over South America: A simulation study of total electron content, J. Atmos. Sol.-Terr. Phys., 68, 18191833, doi:10.1016/j.jastp.2006.05.025, 2006.

M. T. A. H. Muella (e-mail: mmuella@dae.inpe.br), E. R. de Paula, C. N. Mitchell, P. M. Kintner, R. R. Paes, and I. S. Batista 